always resulted in a marked diminution of sensitivity of night vision. Similar effects are produced by the ideas of sweet and bitter. The idea of the sensation always produced a change, and invariably in the direction which would have resulted from the action of the excitor itself. Emotionally pleasant ideas invariably enhanced the sensitivity of all the sense organs. The idea of weak excitors produced the same effect as the weak excitors themselves. The opposite effect was produced by the idea of strong excitors, for example, of very sour substances or of uncomfortably hot water.

It has been demonstrated in my laboratory that sensitivity to red light increases after action on the eye of its complement green light, and vice versa, although in a lesser degree. This is likewise true of yellow light and its complement, blue light (Schwarz). We now find that the idea of red or yellow light increases the sensitivity of the eye to its complement (green or yellow light), but that the idea of the latter does not have the same effect.

The researches here briefly deseribed transcend the bounds of physiological optics and are of great value for our understanding and quantitative evaluation of certain aspects of the influence of the mind on the physical state in man, and, in particular, on the functional state of the sense organs.

Psychophysiological Department,

KRIKOR KEKCHEYEV.

Institute of Psychology,

Academy of Pedagogical Sciences, Moscow.

\section{Demonstration of Mitosis in Animal Cells}

Iv a recent communication, Lloyd ${ }^{1}$ raises the subject of the teaching of mitosis to zoology students. The materials which he recommends are the developing eggs of various species of nematode worms, and his method is a smear technique.

Slides of maturing and cleaving nematode eggs are also used extensively in the United States and in Canada for teaching mitosis to zoology students; and indeod nowadays it is probably correct to say that the practice is general, except in so far as it has been superseded by the use of slides of cleaving teleost eggs. The nematode used is Ascaris equorum Goeze (A. megalocephala Cloquet), the horse-worm, which is always readily available and has the advantage of possessing only a small number of chromosomes. The slides are prepared not by a smear technique, which might prove to be considerably easier, but by sectioning the uterus after the fixation of that organ, or of the whole worm, by one of the drastic methods normal for nematodes. Before embedding, the uterus is sometimes bent backwards and forwards upon itself so that each final slide contains numerous sections from several different levels and shows many different stages of mitosis. For a zoologist, these sections of Ascaris are in every way superior to those of root tips, and they are as suitable for first-year classes as for advanced students.

However, as an alternative which is considered by some to be even better, whitefish eggs in early stages of cleavage are now being used increasingly (whitefish is a salmonid species, Coregonus clupeiformis Mitchill, common in the Great Lakes). Although these eggs are not so readily available, they are easy to prepare in that fixation is simple and sectioning is unnecessary; slides are being marketed in in- creasing numbers by the large American biological supply houses which had previously concentrated almost exclusively on the eggs of Ascaris.

\section{W. S. Bullough.}

Department of Zoology,

McGill University, Montrea]. July 4.

${ }^{1}$ Lloyd, L1., Nature, 155, 636 (1945).

\section{Late Flowering of Horse-Chestnut}

WHILE passing through Paris recently en route to and from Switzerland, I noticed that a number of horse-chestnuts in the streets were still in flowerquite a number on September 11, and a few still on October 4.

On these dates, perhaps a third of the trees showed foliage normal for the time of year. On the remainder, all or most of the leaves were already withered and brown. I understand that this was due to a severe frost, followed by very dry weather in the spring. Of these prematurely withered trees, a considerable proportion showed a few branches or shoots with normal leaves-indeed, greener than those on the trees which had not been damaged by the frost; and a fair number of these green shoots carried flowers. The same phenomenon, but to a lesser extent, was noted among horse-chestnut trees in western Switzerland in late September.

It would seem that the premature damage to the foliage had stimulated the production of new shoots from buds that would normally have developed next spring, some of which managed to flower as well as to produce new leaves. The phenomenon would thus appear to be very similar to the new growth of leaves and sometimes of flowers observed in various trees in London after being wholly or largely defoliated by bomb-blast'. However, the lateness of blossom must, I think, be exceptional.

16 Queen Anne's Gate,

Jutian Huxley. London, S.W.1.

Oct. 9.

1 Daily Sketch, Aug. 16, 1944.

\section{Lantern Slides of Line Drawings}

THe following simple method of making lantern slides of line drawings may be of interest. Where the diagrams are not already available in printed form, they are drawn in white chalk on a blackboard and photographed directly. The photographic negative so obtained is mounted and bound as a lantern slide, the resulting projection on a screen being a black line drawing on a white background.

As compared with the more usual method of draw. ing the diagram in Indian ink, photographing it, and finally printing the slide from the negative, the saving in time and materials is considerable.

In order to produce the best results by our method, the blackboard should be well cleaned, a chisel-end cut on the chalk, and the negative should be slightly under-exposed to minimize traces of background. We have found the method suitable for reproducing diagrams of apparatus and mathematical formulæ. It should be equally suitable for biological drawings. G. D. YARNOLD.

University College, L. Heath. Nottingham. 